\title{
Saúde rural em tempos de pandemia da covid-19
}

Rural health in times of the covid-19 pandemic

Salud rural en tiempos pandémicos de covid-19

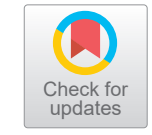

Como citar este artigo:

Silva, Bruno Neves da; Pinto, Erika Simone Galvão. Saúde rural em tempos de pandemia da covid-19. Revista Cuidarte. 2020;11(3):e1265. http://dx.doi.org/10.15649/cuidarte.1265

Revista Cuidarte

Rev Cuid. 2020; 11(3): e1265

doi) $h$ ttp://dx.doi.org/10.15649/cuidarte. 1265

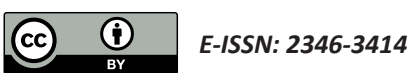

(1) Bruno Neves da Silva ${ }^{1}$

(1) Erika Simone Galvão Pinto²

1 Programa de Pós-graduação em Enfermagem da Universidade Federal do Rio Grande do Norte, Natal, Rio Grande do Norte, Brasil. E-mail: enfbneves@gmail.com Autor para correspondência.

2 Programa de Pós-graduação em Enfermagem da Universidade Federal do Rio Grande do Norte, Natal, Rio Grande do Norte, Brasil.

E-mail: erikasgp@gmail.com

\section{Estimada Editora,}

O contexto rural é um cenário marcado por especificidades próprias, inerentes aos modos de viver e de produzir de seus povos. Historicamente, são cenários marcados por embates populares, disparidades sociais e iniquidades em saúde. A população que re(existe) nessas localidades enfrenta, cotidianamente, vulnerabilidades individuais, sociais e programáticas.

$\mathrm{Na}$ atual emergência de saúde pública ocasionada pelo SARS-CoV-2, causador da COVID-19, doença viral aguda com alto poder de disseminação e com repercussão em diversas realidades globais ${ }^{1}$, deparamo-nos com a seguinte inquietação: os sistemas de saúde, que em muitas realidades já enfrentam um colapso sistemático, conseguirão absorver as demandas de saúde de populações rurais e remotas provocadas pela COVID-19?

Perante às incertezas provocadas por esse questionamento, há de se destacar que a saúde rural já enfrenta um déficit na existência de profissionais de saúde disponíveis, dificuldades de locomoção para a busca de serviços de saúde (grandes distâncias, ausência de transportes) e a própria incipiência desses serviços nas comunidades rurais já é uma realidade consolidada em muitos cenários ${ }^{2,3}$.

A pandemia da COVID-19 agrava essas dificuldades, pois o isolamento social, necessário ao bloqueio da transmissão, implica em diminuição dos transportes já insuficientes para a locomoção da população para os serviços, bem como no deslocamento de profissionais de saúde, que, na maioria das vezes, transitam de outras localidades até a zona rural para atender à população.

Recibido: mayo 25 de 2020

Aceito: junio 16 de 2020

Publicado:septiembre 1 de 2020 $\square *$ Correspondência

Bruno Neves da Silva

E-mail:enfbneves@gmail.com 
Ademais, os serviços de atenção à saúde presentes nos contextos rurais são, majoritariamente, serviços de Atenção Primária à Saúde (APS). No entanto, a atual conjuntura tem enfatizado, recrutado esforços e colocado seu foco na Atenção Terciária.

São investimentos maciços em tecnologias como respiradores mecânicos e construção de hospitais de campanha localizados, em sua quase totalidade, em grandes centros urbanos. Apesar da necessidade existente e da importância inegável desses esforços, a APS, que poderia atuar com protagonismo na prevenção, educação sanitária da população e reabilitação dos indivíduos acometidos pela COVID-19, sobretudo em meio rural, em que representa o único serviço disponível na maioria dos cenários, não tem recebido a atenção merecida.

No entanto, os gestores responsáveis pela formulação das políticas públicas e elaboração de intervenções no sentido de frear o novo coronavírus parecem não se atentar para o óbvio: todo problema de saúde tem início, meio ou fim no território, área de atuação da APS.

Nessa perspectiva, é necessário dar voz a esse nível assistencial de saúde, cujo potencial de resolutividade das demandas de saúde pode chegar a $90 \%{ }^{4}$. Em meio rural, sobretudo, necessita-se fortalecer a APS, para que os problemas de saúde ocasionados pela COVID-19, que já se encontra presente em áreas rurais de diversos países ${ }^{5,6}$, possam ser absorvidos e seu impacto seja atenuado.

A saúde rural é fonte fundamental de conhecimento para o desenvolvimento da APS, a qual é imprescindível para garantir o cuidado de saúde à população rural. A saúde praticada no contexto rural e rururbano possui o potencial de auxiliar na ampliação do conhecimento e desenvolvimento de tecnologias essenciais para o cuidado centrado nas necessidades de saúde, em uma concepção longitudinal e sistêmica, que valoriza a prevenção quaternária? .

Assim, necessita-se da elaboração de políticas públicas que garantam a seguridade social do trabalhador rural, o que perpassa, além da garantia de apoio financeiro, por traçar estratégias que possibilitem seu acesso à saúde, como a otimização de vias de acesso e de transportes, aumento do número de profissionais de saúde disponíveis em áreas rurais e aumento dos turnos de trabalho ou adequação destes à dinamicidade da rotina da população (muitos serviços funcionam apenas em único turno).

Paralelamente a essas medidas, deve-se garantir o fortalecimento da APS, e sua integração com as outras modalidades assistenciais, para salvaguardar a integralidade no acesso da população rural. Ainda que a inquietação inicialmente indagada não possa ser facilmente respondida, acreditamos que a adoção dessas estratégias e o fortalecimento supramencio-
Deve-se garantir o fortalecimento da APS, e sua integração com as outras modalidades assistenciais, para salvaguardar a integralidade no acesso da população rural. nado podem constituir-se nos passos iniciais a serem trilhados para alcançar a equidade em saúde no caminho da roça, diante do atual contexto pandêmico. 


\section{Referências}

1. Xu Z, Shi L, Wang Y, Zhang J, Huang L, Zhang C. et al. Pathological Findings of COVID-19 Associated With Acute Respiratory Distress Syndrome. Lancet Respir Med. 2020; 8(4):420-422. http://doi.org/10.1016/S2213-2600(20)30076-X

2. Garnelo L, Lima JG, Rocha ESC, Herkrath FJ. Acesso e cobertura da Atenção Primária à Saúde para populações rurais e urbanas na região norte do Brasil. Saúde em Debate. 2018; 42(spe1):81-99. https://doi.org/10.1590/0103-11042018s106

3. Arruda NM, Maia AG, Alves LC. Desigualdade no acesso à saúde entre as áreas urbanas e rurais do Brasil: uma decomposição de fatores entre 1998 a 2008. Cad. Saúde Pública. 2018;34(6):01-14. https://doi.org/10.1590/0102-311X00213816

4. Mendes EA. A construção Social da Atenção Primária em Saúde. Brasília, DF: Conselho Nacional de Saúde - CONASS; 2015. Disponível em:

https://www.conass.org.br/biblioteca/pdf/A-CONSTR-SOC-ATEN-PRIM-SAUDE.pdf.

5. Dandachi D, Reece R, Wang EW, Nelson T, Rojas-Moreno C, Shoemaker M. Treating COVID-19 in Rural America. The Journal of Rural Health. 2020; in press. https://doi.org/10.1111/jrh.12457.

6. Brasil. Ministério da Saúde. Boletim Epidemiológico Especial COE-COVID-19. Brasília, DF: Ministério da Saúde; 2020. Disponível em: https://coronavirus.saude.gov.br/boletins-epidemiologicos.

7. Savassi LCM, Almeida MM, Floss M, Lima MC. Saúde no Caminho da Roça. Rio de Janeiro: Editora Fiocruz; 2018. Disponível em:

https://portal.fiocruz.br/livro/saude-no-caminho-da-roca 